\title{
Impact of Pre-service Teachers on P-5 Student Learning: Results of Unit Instructions
}

\author{
Hsiu-Lien Lu \\ National Tsing Hua University \\ hllu@mx.nthu.edu.tw \\ Nancy M. Arrington \\ Georgia Southern University \\ narrington@georgiasouthern.edu \\ Bryan W. Griffin \\ Georgia Southern University \\ bwgriffin@georgiasouthern.edu
}

\begin{abstract}
This quantitative study utilized 1,640 P-5 students' learning outcomes as a result of unit instructions that pre-service teachers gave to P-5 students in the field. The study investigated the difference in P-5 student learning outcomes after a unit instruction by three pre-service teaching practicum course tiers, considering socioeconomic statuses, student grade levels, and subject areas of the content taught by the pre-service teacher. Using normalized gain scores, we used a $t$ test and regression analysis to analyze the data. Based on the findings, recommendations for pre-service teacher education include three items: a) to provide differentiated supervision based on pre-service teachers' experiences and needs, b) to require a proportionate and incremental assignment responding to the amount of pre-service teachers' experiences and hours in the classroom, and c) to incorporate co-teaching opportunities to facilitate peer learning and support in early field experiences.
\end{abstract}

Keywords: student learning outcomes, impact of pre-service teachers, practicum, unit assignments, assessments.

\section{Introduction}

The ultimate goal of teacher education programs is to prepare future teachers to impact student learning outcomes. In What Makes a Teacher Effective, the National Council for Accreditation of Teacher Education (NCATE, 2006) contends that well-prepared teachers outperform those who are not. They additionally proclaim that collaborative relationships between university programs and partner schools have positive impact on the K-12 students and further recommend that more research on teacher education be conducted. Nonetheless, attempting to find evidence in the research and prove the impact of pre-service teachers on student learning outcomes has been persistently problematic. This lack of evidence is mostly due to the fact that the majority of research on teacher preparation programs focuses on the process, rather than student outcomes (Boyd, Grossman, Lankford, \& Wyckoff, 2009).

Although it is not an easy task, literature urges that teacher education programs systematically collect data to determine pre-service teachers’ impact on students' achievement 
(Clark, 2012; Wilson, Floden, \& Ferrini-Mundy, 2001), which reflects the immediate purpose of our study. In order to systematically investigate pre-service teachers' impact on student learning, our study collected unit instruction assignments completed by P-5 pre-service teachers after they completed working in tiers, a sequence of field experiences. In addition to the immediate purpose, this study aimed to address the effectiveness of our program field experiences at different tiers for preparing pre-service teachers and how the field experiences impacted P-5 student learning. Specifically, the research addressed questions regarding: a) whether there are differences in P-5 student learning outcomes following a unit instruction by tiers of pre-service teachers, and b) whether there are differences in P-5 student learning outcomes following a unit instruction among practicum course tiers, considering socioeconomic statuses, student grade levels, and subject areas of the content taught by the pre-service teachers. We then discussed the results based on our program context and made recommendations for future practice and research.

\section{Literature Review}

Literature on pre-service teachers' impact on K-12 student learning outcomes is limited. Nonetheless, the call for attending to the impact of teacher education programs has been constantly conveyed throughout the years. According to Wilson et al. (2001), research on teacher education and the impact of teacher education programs began in the 1960s. Some federal funding supported the research in the 1970s and it gained momentum in the 1980s. Nonetheless, there has been very little sustained support for teacher preparation research.

In the report of the Teacher Preparation Research on current knowledge, gaps, and recommendations prepared for the U.S. Department of Education, Wilson et al. (2001) provided one recommendation specifically related to student achievement. They stated that research on teacher preparation should be explicit about research design and report to improve student outcomes. Although trying to measure the effects of teacher preparation is admittedly complicated, improving student achievement is always the ultimate goal. They therefore encourage the connection "from the design of studies to the interpretation and reporting of results" (p.34).

Regardless of the fact that it is difficult to gather student achievement data, some studies report findings in this area. Clark's (2012) investigating the impact of pre-service teachers on both mathematics achievement and attitudes of P-5 students at a Colorado School was one example. Her findings proposed that pre-service teachers can positively impact the achievement and attitudes of the P-5 students. Hedrick (1999) reported a study that involved pre-service teachers who tutored one-on-one with their students in $3^{\text {rd }}, 4^{\text {th }}$, and $5^{\text {th }}$ grade reading classrooms for a year. Utilizing portfolios that included daily running records, comprehension assessments, and writing samples collected by the tutors, the author analyzed the students' beginning and ending reading levels. The results of this study revealed significant advancement to the young students' reading levels. Furthermore, Stuart and Thurlow (2000) investigated 26 pre-service teachers' experiences, beliefs, and classroom practices. Part of their findings covering the impact of pre-service teachers' beliefs on P-5 students' mathematics achievement and attitudes suggested that pre-service teachers can positively impact the achievement and attitudes of P-5 students.

One noteworthy point in available literature is the dearth of details about how pre-service teachers impact their P-12 students' outcomes. In addition to the abovementioned literature, 
other studies such as those of Broaddus (2000), Knowles (1992), and Smith and Strahan (1997) presented their writings in case studies as candidates reflected on their experiences with P-12 students. While working with the students in reading or math in the field, the pre-service teachers were provided opportunities to focus on the individuality of the learners. The prolonged engagement with students allowed pre-service teachers to move beyond the focus on their own processes, materials, and strategies, and to begin making instructional decisions based on the student outcomes. Consequently, although the focus of the studies was on the pre-service teachers' progress, outcomes indicated that the pre-service teachers became more aware of the level of questioning and expectations of their young students. This awareness led them to adjust their questioning and expectation levels and help students achieve at a higher level. The preservice teachers' reflections in these case studies demonstrated that the P-12 students benefit from pre-service teachers' knowledge of the individual child and higher level of instruction. How pre-service teachers' impact on P-12 student learning in the literature; therefore, derives mainly from pre-service teachers' reflection on their field experiences.

The Oregon teacher licensure system serves as a model that emphasizes student learning outcomes and not the knowledge and skills of the teachers. For example, prospective teachers in the system are required to provide evidence of their impact on all their students' learning during two separate units of instruction (Schalock, Schalock, \& Myton, 1998). The focus becomes centering on student learning and encourages candidates to assess student learning and using the assessment outcomes to foster the students' learning progress. As a result, teaching practices in this system change and gains are shown in students' learning.

Further supporting this idea is Darling-Hammond (2003), who in The effects of initial teacher education on teacher quality suggested four factors that contribute to teachers' influence on student achievement: a) Emphasizing the importance of focusing pre-service training on the P-12 student outcomes, b) the factors include content area training, c) diversity training in preservice and d) professional development, thinking skills training, and hands-on training.

Recognizing the importance of pre-service teacher education, U.S. Secretary of Education Arne Duncan (2009) also advocated a trend of moving the focus from what and how pre-service teachers do, to how and what they can do to impact student learning. In a speech addressing to the Teachers College of Columbia University, Duncan explicitly upheld that "America’s great educational challenges require that this new generation of well-prepared teachers significantly boost student learning and increase college-readiness.”

\section{Method}

This quantitative study utilized authentic student learning outcomes as a result of unit instructions that pre-service teachers gave to P-5 students in the field. The study lasted a semester and posed little research effect on P-5 students and pre-service teachers, as the data were required assignments of pre-service teachers' courses that focused on field experiences in the program. The advantage of using authentic data was that it allowed the researchers to assess the unaffected impact that pre-service teachers had on P-5 students' learning.

\section{Settings}

The settings of this study are a P-5 teacher education program at a university in the southeast region in the U.S. and 15 P-5 schools where we place pre-service teachers in classrooms and are 
within a 60-mile radius of the campus. Among the schools, one serves a population that included $0-19 \%$ of the students with an economically disadvantaged status, two have $20 \%-47 \%$, five $48 \%-64 \%$, and seven $65 \%$ and more of the students at an economically disadvantaged status.

In early childhood teacher education, pre-service teachers are in junior or senior years and enroll in the three successive practicum course tiers, Methods I, Methods II, and Student Teaching. They are placed in classrooms working with university supervisors and cooperative teachers based on the requirement of diverse placement. Each classroom they are placed in has around 15 to 30 students.

Pre-service teachers in each practicum course tier are placed based on their experiences and work with different grade levels for varied hours in the field. Methods I students are placed in K-2 classrooms in groups of three or pairs working with P-5 students in the morning for four hours on Tuesday and Thursday in the first 10 weeks of the semester, and thereafter four hours every morning in the last five weeks of the semester. Altogether, they work in the classroom for 180 hours. In Methods II, pre-service teachers work in grade-3-5 classrooms in pairs full day for 10 weeks, altogether 400 hours in this experience. Student Teaching is the last stage of practicum in the program and pre-service teachers work with P-5 students all day, with a total of 600 hours in the classroom individually for the entire semester.

The program maps out differentiated supervision and assignments proportionate to each practicum tier based on pre-service teachers' experiences in the field. Pre-service teachers in Methods I are required to design a culminating 3-day unit on language arts or social studies, get approved by the university supervisor and cooperating teacher, and teach it to the students. Before planning the unit, they conduct a content research on which they base to plan a preassessment, evaluate student ability on the topic, and use the pre-assessment results to adjust the curriculum and plan a unit. After the instruction, P-5 students take the post- assessment the same as the pre-assessment. A culminating 5-day unit for pre-service teachers in Methods II covers science or math. Pre-service teachers in Methods II conduct a pre- and post- assessment following similar procedures as those in Methods I tier. Pre-service teachers in Student Teaching plan, teach, and evaluate a 10-day unit on a subject suggested by cooperating teachers. They follow similar procedures regarding the unit planning, teaching, and assessing using the same pre- and post- assessments as those in the Methods I and Methods II course tiers. More details of the field experiences in each practicum level are provided in Table 1.

Table 1. Practicum Tiers and Field Experience Descriptions

\begin{tabular}{|c|c|c|c|}
\hline Characteristic & Methods I & Methods II & Student Teaching \\
\hline Entering the field & $\begin{array}{l}\text { Second semester, } \\
\text { Junior }\end{array}$ & First semester, Senior & $\begin{array}{l}\text { Second semester, } \\
\text { Senior }\end{array}$ \\
\hline $\begin{array}{l}\text { Courses taken } \\
\text { alongside Practicum }\end{array}$ & $\begin{array}{l}\text { Language and } \\
\text { Literacy, Creative } \\
\text { Arts, \& Social } \\
\text { Studies }\end{array}$ & Math, Science, \& PE & $\begin{array}{l}\text { Seminars (support of } \\
\text { portfolio } \\
\text { development) }\end{array}$ \\
\hline Levels of supervision & $\begin{array}{l}\text { Four 3-hr orientations } \\
\text { whole group; } \\
\text { Full attention from } \\
\text { US; Limited attention } \\
\text { from CS }\end{array}$ & $\begin{array}{l}\text { Two 3-hr orientations } \\
\text { whole group; two 3- } \\
\text { hr orientations with } \\
\text { US; Equal attention } \\
\text { from US and CS }\end{array}$ & $\begin{array}{l}\text { One orientation } \\
\text { before semester on } \\
\text { portfolio and } \\
\text { licensure process; } \\
\text { Primary attention } \\
\text { from CS }\end{array}$ \\
\hline
\end{tabular}

Journal of the Scholarship of Teaching and Learning, Vol. 18, No. 2, June 2018. josotl.indiana.edu 


\begin{tabular}{|c|c|c|c|}
\hline Types of placement & $\begin{array}{l}2-3 \text { PT in the same } \\
\text { classroom }\end{array}$ & $\begin{array}{l}2 \text { PT in the same } \\
\text { classroom }\end{array}$ & $1 \mathrm{PT}$ in the classroom \\
\hline Grade levels & $\mathrm{K}-2$ & $3-5$ & $\mathrm{~K}-5$ \\
\hline Teaching subjects & All & All & All \\
\hline Unit Length & 3-day & 5-day & 10-day \\
\hline Unit Subjects & $\begin{array}{l}\text { *Language Arts or } \\
\text { Social Studies } \\
\text { (*preferred) }\end{array}$ & $\begin{array}{l}\text { *Math,* Science, } \\
\text { Social Studies, or } \\
\text { Language Arts } \\
\text { (*preferred) }\end{array}$ & $\begin{array}{l}\text { Any one of the four } \\
\text { subject areas }\end{array}$ \\
\hline $\begin{array}{l}\text { Hours in the } \\
\text { classroom }\end{array}$ & 180 hours & 400 hours & 600 hours \\
\hline
\end{tabular}

\section{Samples}

We included 1,640 effective P-5 samples in this study. These P-5 students were selected because they were taught by 71 pre-service teachers who responded to our request submitting useable P-5 students' pre- and post- assessment results. Unfortunately, data from three pre-service teachers were discarded as they were not decodable or quantified, with 68 pre-service teachers' student learning data usable. Effective 68 responding pre-service teachers were among a total of 211 who enrolled in the program and were recruited, with a response rate of $32.2 \%$.

Among the 1,640 effective P-5 samples (see Table 2), 507 P-5 students came from Methods I classrooms, 646 from Methods II classrooms, and 487 from Student Teaching classrooms. Of all P-5 students, 229 were kindergarteners, 295 first graders, 121 second graders, 539 third graders, 91 fourth graders, and 365 fifth graders. Among subjects taught, 792 P-5 students were taught in language arts, 80 in health, 104 in math, 321 in social studies, and 343 in science. P-5 students' race and gender were not clear because they were identified in the assignment as numbers to protect their confidentiality. Of all the P-5 students, 68 were in schools with $0 \%$ to $19 \%$ of the students at an economic disadvantage, 286 were in schools with $20 \%$ to $47 \%$ of the students at an economic disadvantage, 440 in schools with $48 \%$ to $64 \%$ of the students at an economic disadvantage, and 846 in schools with $65 \%$ and more of the students at an economic disadvantage, which reflected the SES facts of the regions that the program works with.

Table 2. P-5 Students' Demographic Information

\begin{tabular}{|c|c|c|c|c|c|c|}
\hline \multicolumn{7}{|l|}{ Category } \\
\hline \multirow[t]{2}{*}{ Classrooms } & MI & MII & ST & & & \\
\hline & 507 & 646 & 487 & & & \\
\hline \multirow[t]{2}{*}{ Grade Level } & $\mathrm{K}$ & 1 & 2 & 3 & 4 & 5 \\
\hline & 229 & 295 & 121 & 539 & 91 & 365 \\
\hline \multirow{2}{*}{ Subject } & Language Arts & Health & Math & Social Studies & Science & \\
\hline & 792 & 80 & 104 & 321 & 343 & \\
\hline \multirow{2}{*}{ SES } & $0 \%-19 \%$ & $20 \%-47 \%$ & $48 \%-64 \%$ & $65 \%$ and above & & \\
\hline & 68 & 286 & 440 & 846 & & \\
\hline
\end{tabular}




\section{Data Sources and Collection}

Pre- and post- assessments designed and administered for unit instructions by the three practicum course tiers were the sources of data that evidenced P-5 student learning outcomes for this study. The unit is a critical and culminating assignment that the pre-service teacher designs and teaches in his/her specific field experience required by the program. The unit assignments for the three practicum course tiers are established as a program and each unit assignment adapts to the preservice teachers' stage of learning. The unit design is informed by pre-assessment results, deliberated based on the developmental stages of the P-5 students in the class, and supervised and monitored by the university supervisor and the cooperating teacher. As a result, each unit can be as unique as the instructed group of students. After completion of the unit instruction, the pre-service teacher is required to analyze the outcomes of the pre- and post- assessments organized in tables, charts or bars. The outcomes of the assignments indicate the pre-service teachers' teaching and learning toward becoming teachers and were what we utilized in this study.

The data collection took several steps to complete. We firstly gained the program consent to conduct this study. After obtaining instructors' support through program meetings, we explained the study to the pre-service teachers and invited them to sign the informed consent if they agreed to participate. Finally, at the end of the semester, the researchers collected the analyzed results of the unit assessments electronically from the pre-service teachers.

\section{Validity}

The designs and implementations of pre-assessments, units and post assessments were closely monitored through experienced specialists, i.e., university supervisors and cooperating teachers to ensure the validity of the study. In the program, all unit designs are proportionally supervised by university supervisors and cooperating teachers based on the teaching experiences that preservice teachers have in the field. Specifically, Methods I pre-service teachers, who have the least teaching experience, received the most intensive clinical supervision from university supervisors primarily and supported by cooperating teachers in the content. After obtaining a topic for the unit, each Methods I pre-service teacher conducts a content research, communicates with their cooperating teacher, and warrant an appropriate content for the unit. Approved by both the cooperating teacher and the university supervisor, pre-service teachers administer a preassessment to their students and use the results to further inform the unit design. Once finishing instructing the unit, the pre-service teacher administers the post assessment the same one as the pre-assessment. Methods II pre-service teachers followed the same procedures as those in Methods I and received similar support from both the university supervisor and the cooperating teacher, yet with a less degree of intensity due to the experience that they had obtained in Methods I. After the two former course tiers, pre-service teachers in Student Teaching generally demonstrate a higher level of competency in planning. As a corollary, pre-service teachers in this tier rely mostly on cooperating teachers' guidance and consultation for their unit design. The role of university supervisors then turns primarily to the oversight of the design of teaching strategies and management plans, and ensure that all aspects of the unit design reflect the program's expectations.

There was a concern that the achievement data were derived from pre-service-teachermade tests with varying difficulty levels. It is not possible to provide a complete review of all 
pre-service teachers' tests since the study contained more than 1,000 such tests in various subject areas, grade levels and in varying school populations. In order to make the data more comparable across the variety of conditions included in this study, we employed normalized gain scores before analysis (Bao, 2006).

\section{Data Analysis}

Although all pre-service teachers follow the same guidelines of the unit assignments provided by the program, the student achievement data for this study were difficult to interpret and compare. It was because the data were derived from many pre-service teachers who provided instruction across a variety of content areas and grade levels. Moreover, the achievement data were from pre-service-teacher-made tests with varying difficulty levels. To make the data more comparable across the variety of conditions included in this study, we employed normalize gain scores before analysis (Bao, 2006).

\section{Gain and Change Scores}

Normalized gain, symbolized by g, represents the proportion improvement of what could be improved from pre-assessment to post-assessment. For example, suppose a student scores 40 out of 100 correct on a pre-assessment. The amount of improvement possible from the preassessment score is $100-40=60$. Suppose further that this student scores 70 on the postassessment. The increase from pre-assessment to post-assessment is 30 points, and this 30 points represents a 50\% increase over the pre-assessment score in terms of what could be gained, i.e., gain of 30 divided by the possible gain of 60 is $30 / 60=.50$ or $50 \%$. Similarly, a student who obtains a pre-assessment score of 90 has only 10 points of possible improvement on the postassessment to obtain a maximum score of 100. If this student scores 93 on the post-assessment, that represents a $30 \%$ increase over what could have been gained, i.e., a 3 point increase from post-assessment to pre-assessment $(93-90=3)$ which is divided by the maximum possible gain of 10 points (maximum score minus pre-assessment score is $100-90=3$ ). Thus, this second student has a normalized gain score of $3 / 10=.30$ or $30 \%$.

The formula for normalized gain is provided by Bao (2006):

$$
\mathrm{g}=\frac{\text { Post-assessment Score }- \text { Pre-assessment Score }}{\text { Maximum Score }- \text { Pre-assessment Score }}
$$

For this study we calculated normalized gains from percentage scores, so the formula presented by Colettaa and Phillips (2005) was used:

$$
g=\frac{\text { Post-assessment } \%-\text { Pre-assessment } \%}{100 \%-\text { Pre-assessment } \%}
$$

where post-assessment \% was percentage correct on the post-assessment and pre-assessment \% was the percentage correct on the pre-assessment.

By using the normalized gain score the focus shifts from absolute test scores to relative gains, so the focus of this study was not on absolute gains which may differ greatly across the variety of pre-service teacher-made tests employed, but instead on the relative gain each preservice teacher was able to foster from their students.

One problem with normalized gain occurs when a post-assessment score is lower than the corresponding pre-assessment score (i.e., post-assessment < pre-assessment). In this situation the interpretation of normalized gain fails and the calculated values no longer represent the portion 
gain or change relative to what could be gained. When post-assessment < pre-assessment, Marx and Cummings (2007) proposed the following formula:

$$
\mathrm{g}=\frac{\text { Post-assessment } \%-\text { Pre-assessment } \%}{\text { Pre-assessment } \%}
$$

This formula provides a change score that presents the proportion loss from the preassessment starting position. This interpretation is more consistent with normalized gain, although the focus with this formula is loss from where one started. For situations in which preassessment scores were greater than post-assessment scores in this study, we calculated and converted the normalized change score to a percentage loss.

Another problem occurs when a pre-assessment score and a post-assessment score are both $100 \%$. In this situation, the student has reached the utmost score for both tests. Therefore, the normalized gain would be 100 for this student.

\section{Analysis Approaches}

After P-5 students' performances were converted to normalized gain scores, we used two analysis approaches to find answers to the inquiry questions: a $t$ test to examine differences in the normalized gain scores and a set of regression tests to investigate the differences in the student learning outcomes among practicum tiers, subject areas, social economical statuses, and grade levels.

The data for this study formed a natural clustering of K-5 students grouped by pre-service teachers. Taking into account the clustering of observations, we used a linear mixed model (Fitzmaurice, Laird, \& Ware, 2011), also known as a multilevel model (Snijders \& Bosker, 2012) or hierarchal linear model (Raudenbush \& Bryk, 2002), to regress normalized gain scores on the four predictors examined. This model avoids standard errors and hypothesis tests that will be incorrect and lead to Type 1 errors -- indicating there are differences when there are not.

\section{Mixed Model of Student Learning Outcomes}

We used the following random intercept model (Rabe-Hesketh \& Skrondal, 2005) for normalized gain scores in a linear mixed model:

$(\text { Normalized Gain })_{\mathrm{ij}}=\gamma_{00}+\sum \alpha(\text { Course })_{\mathrm{ij}}+\sum \beta(\text { Economic Status })_{\mathrm{ij}}+\sum \chi(\text { Grade Level })_{\mathrm{ij}}$

$$
+\sum \delta(\text { Subject Area })_{i j}+e_{i j}+\pi_{0 j}
$$

In summary, we can understand the components of this model as follows:

$\gamma_{00}$ is the mean normalized gain controlling for the four predictors;

$\sum \alpha(\text { Course })_{\mathrm{ij}}$ are dummy variables for pre-service teachers' course of study (i.e., Methods I, Methods II, or Student Teaching);

$\sum \beta$ (Economic Status $)_{\mathrm{ij}}$ are dummy variables for the economic status of the school in which students are enrolled (i.e., percentage of students on free or reduced lunch);

$\sum \chi(\text { Grade Level })_{\mathrm{ij}}$ are dummy variables represent student grade level (i.e., K through $5^{\text {th }}$ );

$\sum \delta$ (Subject Area) $)_{\mathrm{ij}}$ are dummy variables for content subject area (e.g., Mathematics, Science, etc.);

$\mathrm{e}_{\mathrm{ij}}$ is the student level error term, and

$\pi_{0 \mathrm{j}}$ is modeled effect of pre-service teacher $\mathrm{j}$ on normalized gain controlling for the other modeled predictors. 


\section{Results}

Inquiry Question \#1

Are there differences in P-5 student learning outcomes after a unit instruction by pre-service teachers? The analysis of student performance was conducted in order to learn whether the gain demonstrated by P-5 students was greater than would be expected by chance. To assess gain, we performed a one-sample $t$-test. Results showed that the mean normalized gain score was $\mathrm{M}=$ $65.06 \%$ ( $\mathrm{sd}=38.79, \mathrm{n}=1640$ ), and this level of gain was statistically significant at the .05 level $(\mathrm{t}=67.93, \mathrm{df}=1639, \mathrm{p}<.05,95 \% \mathrm{CI}=63.19,66.94)$. This finding indicates a statistically significant difference in P-5 student learning outcomes following a unit instruction by preservice teachers and suggests that P-5 students significantly benefiting from pre-service teacher unit instruction and demonstrating improvement over their pre-assessment scores.

\section{Inquiry Question \#2}

Are there differences in P-5 student learning outcomes after a unit instruction among practicum course tiers, considering socioeconomic statuses, student grade levels, and subject areas of the content taught by the pre-service teachers? We addressed this question by the regression models as follows.

\section{Sources of gain}

This set of analyses focused on determining whether student achievement normalized gains differed by practicum course tier (Methods I, Methods II, and Student Teaching), socioeconomic status (0-19\%, $20 \%$ to $47 \%, 48 \%$ to $64 \%$, and $65 \%$ and above economically disadvantaged), student grade level (kindergarten, 1, 2, 3, and $4+5$ ) , and subject area of the content taught by the pre-service teacher (Social Studies, Language Arts, Science, and Mathematics and Health). We presented mean normalized gain scores for each of these four factors in Table 3.

Table 3. Descriptive for Student Normalized Gains by Pre-service Course Tier, School Economic Status, Student Grade Level, and Subject Area $(\mathbf{N}=1640)$

\begin{tabular}{llll}
\hline Variable & Mean Normalized Gain & SD & $\mathrm{n}$ \\
\hline Course Tier & & & \\
$\quad$ Methods I & 68.16 & 45.57 & 507 \\
$\quad$ Methods II & 62.29 & 37.47 & 646 \\
$\quad$ Student Teaching & 65.52 & 32.06 & 487 \\
Socioeconomic Status & & & \\
$\quad$ 0 to 19\% & 83.87 & 28.05 & 68 \\
20 to 47\% & 64.14 & 43.70 & 286 \\
48 to 64\% & 67.87 & 34.97 & 440 \\
65\% or more & 62.40 & 39.20 & 846 \\
Grade Level & & & \\
$\quad$ Kindergarten & 63.30 & 43.29 & 229 \\
$\quad$ Grade 1 & 75.14 & 39.04 & 295 \\
$\quad$ Grade 2 & 60.46 & 48.76 & 121
\end{tabular}

Journal of the Scholarship of Teaching and Learning, Vol. 18, No. 2, June 2018. josotl.indiana.edu 


\begin{tabular}{llll} 
Grade 3 & 68.32 & 36.33 & 539 \\
Grade 4 & 69.53 & 25.63 & 91 \\
Grade 5 & 53.63 & 35.07 & 365 \\
Lject Area & & & \\
Language Arts & 65.22 & 42.36 & 792 \\
Health & 57.70 & 28.74 & 80 \\
Mathematics & 68.40 & 30.95 & 104 \\
Science & 68.40 & 33.47 & 321 \\
Social Studies & 62.30 & 38.71 & 343 \\
\hline
\end{tabular}

\section{Mixed Regression Model}

We obtained model estimates using maximum likelihood (StataCorp., 2011) and Table 4 contains regression estimates.

Table 4. Mixed Regression Model of Normalized Gain $(\mathrm{N}=1640)$

\begin{tabular}{|c|c|c|c|c|c|c|c|}
\hline Fixed Portion of Model & $\mathrm{B}$ & se b & $95 \% \mathrm{CI}$ & & $\operatorname{LR} \chi^{2}$ & $\mathrm{df}$ & p-value \\
\hline Course Tier & & & & & 2.24 & 2 & 0.33 \\
\hline Methods II & -9.83 & 12.22 & -33.78 & 14.13 & & & \\
\hline Student Teaching & 5.15 & 10.82 & -16.06 & 26.35 & & & \\
\hline Socioeconomic Status & & & & & 5.66 & 3 & 0.13 \\
\hline 20 to $47 \%$ & $-36.31 *$ & 17.27 & -70.15 & -2.47 & & & \\
\hline 48 to $64 \%$ & -24.31 & 17.25 & -58.11 & 9.50 & & & \\
\hline $65 \%$ or more & -24.25 & 15.49 & -54.61 & 6.12 & & & \\
\hline Grade Level & & & & & 8.85 & 5 & 0.12 \\
\hline Grade 1 & 11.49 & 7.61 & -3.44 & 26.41 & & & \\
\hline Grade 2 & -7.88 & 9.25 & -26.00 & 10.25 & & & \\
\hline Grade 3 & 9.02 & 12.09 & -14.69 & 32.72 & & & \\
\hline Grade 4 & 6.74 & 17.05 & -26.67 & 40.14 & & & \\
\hline Grade 5 & -11.19 & 12.79 & -36.27 & 13.89 & & & \\
\hline Subject Area & & & & & 1.76 & 4 & 0.78 \\
\hline Health & 8.60 & 16.08 & -22.92 & 40.12 & & & \\
\hline Mathematics & -7.24 & 12.66 & -32.05 & 17.58 & & & \\
\hline Science & -9.19 & 8.27 & -25.40 & 7.03 & & & \\
\hline Social Studies & -6.32 & 7.79 & -21.58 & 8.95 & & & \\
\hline Model Intercept & 94.30 & 16.92 & 61.12 & 127.47 & & & \\
\hline Random Portion of Model & Estimate & se & & & & & \\
\hline Student-level SD & 18.33 & 1.85 & & & & & \\
\hline Pre-service Teacher SD & 33.30 & 0.59 & & & & & \\
\hline $\mathrm{R}^{2}$ (total variance modeled) & 0.055 & & & & & & \\
\hline
\end{tabular}

Note. Each coefficient estimated represents a dummy variable coded 1 if the student belonged to that particular classification or coded 0 if student was not a member of that classification. For example, Grade 1 dummy variable was coded 1 if student was in Grade 1, or coded 0 otherwise. The reference, or comparison, group for each dummy set was Methods I for Course Tier, 0 to 19\% for Socioeconomic Status, Kindergarten for Grade Level, and Language Arts for Subject Area. LR $\chi^{2}$ represents the Likelihood Ratio test chi-square result for variable contribution to the model. $\mathrm{n}=1640$ students taught by 68 pre-service teachers. $* \mathrm{p}<.05$.

Journal of the Scholarship of Teaching and Learning, Vol. 18, No. 2, June 2018. josotl.indiana.edu 
As shown by the model Likelihood Ratio (LR) tests (Snijders \& Bosker, 2012), there are no statistically significant differences in normalized gain scores based upon practicum tier (Likelihood ratio chi-square $=2.24$, $\mathrm{df}=2, \mathrm{p}=.33$ ) after controlling for the other predictors (school economic status, grade level, and subject area). This result suggests P-5 students perform equally well for Methods I, Methods II, and Student Teaching, which is what the program has planned for.

Finally, we attempted several models of interactions for the regression analyses, but none worked because there were not enough students in the various variable category combinations and for several combinations the sample size was 0 . For example, in the model testing for the interaction between Socioeconomic Status and Course Tier, there were eight coefficients to be estimated for the interaction results, but the model was only able to provide estimates for three of the eight coefficients. The others were reported as "0 (empty)" and this means they could not be estimated due to no information or small cell sizes. Further discussion follows in next section.

\section{Discussion and Conclusion}

The findings indicate that there is a significant difference in P-5 student learning outcomes after a unit instruction by the pre-service teachers. On the other hand, the findings reveal that there is no difference in P-5 student learning outcomes after a unit instruction among practicum course tiers, controlling for socioeconomic statuses, student grade levels, or subject areas of the unit content taught by the pre-service teacher. The results infer that the P-5 students significantly benefited and performed equally well in learning the unit taught by the pre-service teachers in the three practicum tiers.

Based on the results, a question arises: How could this be possibly true with the preservice teachers coming with varied levels of experiences? This question is especially comprehensible with the conflict found in the literature reporting that the more experienced preservice teachers are in the field, the more effective they are in helping students learn (Boyd et al., 2009; Darling-Hammond, 2003b; Wilson et al., 2001). The answer to the question may not be judicious unless otherwise justified through and grounded in the program context, about which we would like to articulate further.

First, the results indicate no significant difference in P-5 student learning outcomes following the unit instruction among practicum tiers. The justification of this phenomenon may be the discriminated clinical supervision underwritten by the program and the unit assignments proportionate to each practicum tier. The mass and intensity of supervision provided to preservice teachers in each tier of the practicum are based on where their experiences are and what they need. Therefore, the least experienced group of students in Methods I receive the most support from university supervisors in the planning and implementation of the unit, less in Methods II, and the least in Student Teaching. Additionally, the length and weight of the unit assignments required in each tier vary in accordance to the pre-service teachers' ability and time capacity. Method I students are required to plan and implement a 3-lesson unit working altogether 180 hours during the semester at a lower grade level, while Method II a 5-lesson unit working 400 hours at an upper grade level and Student Teaching a 10-lesson unit working 600 hours at any P-5 grade level assigned. The varied assignments based on experiences and hours in the classroom may reflect a sensible consideration of the program concerning pre-service teachers' ability and capacity in working with P-5 students. Collectively, the differentiated supervisory supports and proportionate assignments may be critical in empowering pre-service

Journal of the Scholarship of Teaching and Learning, Vol. 18, No. 2, June 2018. josotl.indiana.edu 
teachers in the way that it helps generate success and promote confidence in the classroom. Furthermore, co-teaching opportunities may be helpful for pre-service teachers with less experience. Methods I pre-service teachers are placed in three or pairs in the classroom, Methods II in pairs, and Student Teaching individually. This placement strategy could potentially be a factor beneficial to the achievement at these first two tiers. As suggested by Graziano and Navarrete (2012), addressing the diverse needs in a classroom through co-teaching contributes to increased student achievement, which may provide an explanation to this result.

Second, the results indicate no statistically significant differences in P-5 student learning outcomes among the three practicum course tiers based on students' socioeconomic backgrounds and grade levels, as well as the subjects. The justification of this phenomenon again points to the collaborative practice of clinical supervision with which university supervisors and cooperating teachers support and build pre-service teachers up in planning and implementing the unit. Preservice teachers work diligently with university supervisors, design and implement a unit on language arts and social studies in Methods I while cooperating teachers ensure that the content is right. Pre-service teachers in Methods II work with university supervisor and cooperating teachers collaboratively. Throughout Student Teaching, cooperating teachers supervise preservice teachers' planning and teaching of a unit on an assigned subject. Close and vigilant supervision from both mentors may have promoted pre-service teachers at varied tiers so that they could effectively engage students during their unit instruction. Therefore, the effectiveness of pre-service teachers at varied tiers may have contributed to the findings that no significant differences were found in P-5 student learning outcomes following a unit instruction among practicum course tiers regarding student SES statuses, grade levels and subject areas of the content taught by the pre-service teachers.

\section{Limitations of the Study}

One limitation of this study was that we were not able to analyze the interactions among variables because empty values existed via the linear mixed model. However, it is an inevitable matter due to the settings structured in the program. The program organizes tiered field experiences the way that Methods I pre-service teachers are placed in K-2 classrooms, Methods II in 3-5 classrooms, and Student Teaching in K-5 classrooms. Additionally, the requirement of diverse placement urges pre-service teachers to work in diverse socioeconomic status settings. Consequently, there are intrinsically empty values in the variables of Economic Status and Course Tier among the three practicum tiers per the program design.

Another limitation was that some collected data were not usable and discarded because the data were not presented in a format that could be decoded or quantified. Given that the program provides instruction for analysis of the assessment results, unfortunately, the assignments of three pre-service teachers were not measured the way that could be properly calculated, with approximately 70 P-5 students' learning outcomes in language arts and math respectively excluded. With this limitation, we recommend that teacher education programs devote efforts to teaching pre-service teachers how to quantify and use the assessment results to their instruction. It is not easy yet critical for pre-service teachers to appropriately quantify, analyze and interpret assessment results they obtain from instruction, a skill that will help preservice teachers present, interpret, and use assessment data to inform their instruction in the future when they have their own classrooms; and an essential skill to have in the era of accountability (Brimijoin, Marquissee, \& Tomlinson, 2012; Darling-Hammond, 2003). 
Additionally, our pre-service teachers are still getting to know their young learners and are developing their skills on assessing diverse learners; and they are challenged as they create equitable assessments (assessments which are most appropriate for the diverse learners in the classroom, such as their language ability and culture) and provide appropriate feedback and adaptations of their instruction (Siegel, 2014). We concur with recommendations in recent studies that courses or seminars focusing specifically on assessment of student learning would enhance our students' ability to assess student learning, build upon the assessment skills necessary for their future classrooms, and contribute to a more positive attitude toward assessment, which helps optimize their efficacy for administering and analyzing appropriate assessments with their students (Darling-Hammond, 2003; McGee \& Colby, 2014; Siegel, 2014).

\section{Recommendations for Future Practice and Research}

Based on the findings, the context of our study serves as critical learning components for preservice teachers and allows their instructions to impact P-5 student learning. Therefore, recommendations for pre-service teacher education include three items: a) to provide differentiated supervision based on pre-service teachers' experiences and needs, b) to require a proportionate and incremental assignment responsive to the amount of pre-service teachers' experience and hours in the classroom, and c) to incorporate co-teaching opportunities to facilitate peer learning and support in early field experiences.

With the dearth of the literature on pre-service teachers' impact on K-12 student learning, our recommendations for future directions of research resonate with what Clark (2012) suggests. First, the impact on the P-5 students in the schools should not be ignored while field experiences are being studied. Second, more data concerning pre-service teachers' impact on student learning during their practicum experiences should be systematically collected. Another recommendation for future research is that if a study is conducted by arrangement, gender should be considered as one variable to examine the outcomes.

\section{Conclusion}

In conclusion, this study has fulfilled multiple purposes. First, locally, it informs our program and college of pre-service teachers' impact on student learning. As a result, our program will be able to evaluate, adjust, and restructure the practices and assignments to better help the learning of pre-service teachers based on the findings. Second, it extends the knowledge of pre-service teachers' impact on P-5 student learning to the larger professional communities in the world.

The study contributes to the literature in the fact that it provides the details of the context and utilizes data from P-5 students' achievements and it also attends to all subject areas, social economic statuses, and grade levels of P-5 students, which extends the efforts of former researchers in this area (Boyd et al., 2009; Clark, 2012; Stuart \& Thurlow, 2000; Wilson et al., 2001). The emphasis on student outcomes in this study enhances the results of recent studies (Clark, 2015; McGee \& Colby, 2014; Siegel \& Wissehr, 2011; Simon, Chitpin, \& Yahya, 2010) on pre-service teachers' process of, attitudes toward, and development of assessment skills/literacy by demonstrating that higher efficacy and more positive attitudes toward assessment can positively impact the P-5 learners' achievement. Finally, the study provides the potential to benefit others who are interested in the same topic for future practice and research.

Journal of the Scholarship of Teaching and Learning, Vol. 18, No. 2, June 2018. josotl.indiana.edu 


\section{References}

Bao, L. (2006). Theoretical comparisons of average normalized gain calculations. Physics Education Research, 74, 917-922.

Boyd, D. J., Grossman, P. L., Lankford, H., Loeb, S, , \& Wyckoff, J. (2009). Teacher Preparation and Student Achievement. Educational Evaluation and Policy Analysis, 31, 416-440. doi:10.3102/01623709353129

Brimijoin, K., Marquissee, E., \& Tomlinson, C. A. (2012). Using data to differentiate instruction. Educational leadership, 60(5), 70-70.

Broaddus, K. (2000). From peacemaker to advocate: A pre-service teacher's case study of an emergent reader. Journal of Literacy Research, 32, 571-597. doi:10.1080/10862960009548096

Clark, J. (2012). The impact of pre-service teachers on the mathematics achievement and attitudes of P-5 students at a Colorado school. (Paper Code: CLA04478). Flinders University, South Australia.

Clark, J. (2015). "My assessment didn't seem real": The influence of field experiences on preservice teachers' agency and assessment literacy. Journal of Social Studies Education Research, 6(2), 91-111.

Colettaa, V. P., \& Phillips, J. A. (2005). Interpreting FCI scores: Normalized gain, preinstruction scores, and scientific reasoning ability. American Journal of Physics, 74, 1172-1182.

Darling-Hammond, L. (2003). The effects of initial teacher education on teacher quality. Paper presented at the 2003 Australian Council for Educational Research Annual Conference, Melbourne, Australia.

Duncan, A. (2009). Teacher preparation: reforming the uncertain profession-Remarks of Secretary Arne Duncan at Teachers College, Columbia University. Retrieved from http://www2.ed.gov/news/speeches/2009/10/10222009.html.

Fitzmaurice, G. M., Laird, N. M., \& Ware, J. H. (2011). Applied longitudinal analysis (2 ed.). Hoboken, N.J: Wiley.

Graziano, K. J., \& Navarrette, L. A. (2012). Co-teaching in a teacher education classroom: Collaboration, compromise, and creativity. Issues in Teacher Education, 21(1), 109-126.

Hedrick, W. B. (1999). Pre-service teachers tutoring 3rd, 4th, and 5th graders one-on-one within the school setting. Reading Research and Instruction, 38(3), 211-219.

Knowles, J. G. (1992). Models for understanding pre-service and beginning teachers' biographies: Illustrations from case studies. In L. F. Goodson (Ed.), Studying teachers' lives (pp. 99-152). New York: Teachers College Press. 
Marx, J., \& Cummings, K. (2007). Normalized change. American Journal of Physics, 75(87-91).

McGee, J., \& Colby, S. (2014). Impact of an Assessment Course on Teacher Candidates' Assessment Literacy. Action in Teacher Education, 36(5-6), 522-532.

doi:10.1080/01626620.2014.977753

NCATE. (2006). What makes a teacher effective? A summary of key research findings on teacher preparation. National Council for Accreditation of Teacher Education.

Rabe-Hesketh, S., \& Skrondal, A. (2005). Multilevel and Longitudinal Modeling Using Stata. College Station, TX: Stata Press.

Raudenbush, S. W., \& Bryk, A. S. (2002). Hierarchical Linear Models (2 ed.). Thousand Oaks: Sage Publications.

Schalock, D., Schalock, M., \& Myton, D. (1998). Effectiveness—along with quality—should be the focus. Phi Delta Kappan, 79, 468-470.

Siegel, M. A. (2014). Developing Pre-service Teachers' Expertise in Equitable Assessment for English Learners. Journal of Science Teacher Education, 25(3), 289-308.

Siegel, M. A., \& Wissehr, C. (2011). Preparing for the plunge: Pre-service teachers' assessment literacy. Journal of Science Teacher Education, 22(4), 371-391. doi:10.1007/s10972-011-9231-6

Simon, M., Chitpin, S., \& Yahya, R. (2010). Pre-service teachers' thinking about student assessment issues. International Journal of Education, 2(2), 1-20.

Smith, R. L., \& Strahan, D. (1997). Pre-service middle-level teachers’ orientations toward teaching: Case studies in professional development. Teacher Education Quarterly, 24, 33-50.

Snijders, T. A. B., \& Bosker, R. J. (2012). Multilevel analysis: An introduction to basic and advanced multilevel modeling (2nd ed.). Los Angeles:: Sage.

StataCorp. (2011). Stata longitudinal data/panel dta reference manual: Release 12. College Station, TX: StataCorp LP.

Stuart, C., \& Thurlow, D. (2000). Making it their own: Pre-service teachers' experiences, beliefs, and classroom practices. Journal of Teacher Education, 51(2), 113-121.

Wilson, S. M., Floden, R. E., \& Ferrini-Mundy, J. (2001). Teacher preparation research: Current knowledge, gaps, and recommendations. A research report prepared for the U.S. 